\title{
Diversos nomes para o cansaço: \\ categorias emergentes e sua relação com o mundo do trabalho
}

Rafaela Zorzanelli(a)

Isabela Vieira ${ }^{(b)}$

Jane Araujo Russo(c)

Zorzanelli R, Vieira I, Russo JA. Several names for tiredness: emergent categories and their relationship with the world of work. Interface (Botucatu). 2016; 20(56):77-88.

The objective of this article was, from a sociocultural perspective, to explore the emergence of two clinical entities between 1970 and 1980, which, in the fields of general clinical medicine and psychoknowledge, give names to conditions centered on the symptom of fatigue: chronic fatigue syndrome (ICD-10 G93.3) and burnout (ICD-10 Z73.0). We intend, after a brief presentation of both of these, to analyze the emergence of these two categories, to acknowledge fatigue and exhaustion as symptoms to be medically treated, and to explore similarities and differences between them.

Keywords: Fatigue. Chronic fatigue syndrome. Burnout professional. Work. Medical sociology.
Este artigo tem como objetivo explorar, do ponto de vista sociocultural, a emergência de duas entidades clínicas entre 1970 e 1980 que, no campo da clínica geral e dos saberes psi, nomeiam quadros centrados no sintoma da fadiga: a síndrome da fadiga crônica (CID-10 G93.3) e o burnout (CID-10 Z73.0). Pretendemos, após uma breve apresentação de ambas, analisar o surgimento dessas categorias, para indicar o cansaço e a exaustão como sintomas a serem tratados medicamente e explorar os pontos de aproximação e afastamento entre elas.

Palavras-chave: Fadiga. Síndrome da fadiga crônica. Esgotamento profissional. Trabalho. Sociologia médica.

\footnotetext{
(a) Departamento de Políticas e Instituições em Saúde, Instituto de Medicina Social, Universidade do Estado do Rio de Janeiro (UERJ). Rua São Francisco Xavier, Pavilhão João Lyra Filho, $n^{\circ} 524,7^{\circ}$ andar, blocos D e E. Rio de Janeiro, RJ, Brasil. 20500-013 rtzorzanelli@ hotmail.com (b) Doutoranda, Programa de PósGraduação em Saúde Coletiva, Instituto de Medicina Social, UERJ.

Rio de Janeiro, RJ, Brasil. Bolsista CNPq. isabelamvieira@ gmail.com

(c) Departamento de Políticas e Instituições em Saúde, Instituto de Medicina Social, UERJ. Rio de Janeiro, RJ, Brasil. jane.russo@gmail.com
} 


\section{Introdução}

Analisar duas categorias em vigência na medicina é uma proposta sintonizada com a chamada sociologia do diagnóstico ${ }^{1,2}$, ou seja, o interesse pelo processo de construção (emergência, manutenção ou tempo de vigência) de um diagnóstico. Essa investigação - para que um diagnóstico serve, como é manejado por seus portadores e por profissionais de saúde, por que entra em ascensão ou declínio - pode ser aplicada a diversas categorias médicas em voga, como: transtorno de déficit de atenção e hiperatividade, autismo, disforia de gênero, depressão, fobia social.

O tema do diagnóstico tem estado presente de forma indireta no campo da sociologia médica: é importante, por exemplo, para pensar como o nome de uma doença dá origem à ruptura biográfica ${ }^{3}$; à perda do self ; à reconstrução narrativa ${ }^{5}$. Além disso, ele organiza a experiência da doença, seu tratamento e a direção da cura, e é um projeto interpretativo que envolve troca de experiências entre leigos e especialistas. Pode configurar, assim, uma forma de reapropriação individual da experiência ${ }^{6}$, sendo um esteio para a transformação de particularidades da vida ou de sintomas leves em doenças, o que se poderia chamar de medicalização(d). Interessa-nos notar que o diagnóstico, como realidade classificatória é, antes de tudo, uma classificação médica, mas só sobrevive se oferece alguma utilidade para as instituições sociais, além da medicina, que ajudam a formatá-lo(e).

Não é a primeira vez, na história médica recente, que a fadiga é tratada como objeto, sendo possível afirmar que estamos diante de sua reemergência como signo de doença. Um sinal desta importância histórica é a presença intermitente de quadros patológicos cuja queixa central é a exaustão por mínimo esforço ou a fadiga sem causa orgânica detectável ${ }^{9}$. No ambiente novecentista, esse quadro foi a neurastenia. Atualmente, dois exemplos emblemáticos são a síndrome da fadiga crônica e o burnout, mantidas suas diferenças. O interesse pela comparação entre essas duas categorias prende-se ao fato de ambas localizarem-se nos polos opostos do continuum psicológico/orgânico. O burnout surgiu como um diagnóstico essencialmente psicossocial( ${ }^{(f)}$ no âmbito da psicanálise e da psicologia; ao passo que a síndrome da fadiga crônica é um diagnóstico da clínica geral, que nasce relacionado a suspeitas de infecção viral. Buscaremos discutir o deslizamento entre concepções biológicas e psíquicas operado pela categoria fadiga, no caso desses dois diagnósticos. Tentaremos demonstrar que tal deslizamento tem a ver com contextos históricos e socioculturais distintos.

\section{Síndrome da fadiga crônica}

A Síndrome da Fadiga Crônica (SFC) encontra-se no cenário mais abrangente das chamadas síndromes funcionais, tais como: síndrome do cólon irritável, da Guerra do Golfo, da sensibilidade química múltipla, fibromiálgica, miofascial, dentre outras ${ }^{(g)}$, com as quais compartilha amplamente alguns de seus sintomas. Segundo Wessely ${ }^{12}$, a história da SFC começou com a publicação, no início dos anos 1980, de séries de casos descrevendo uma doença com sintomas semelhantes aos efeitos tardios de uma infecção viral, manifestada por fadiga e outros sintomas aparentemente associados a evidências serológicas de infecções prolongadas pelo vírus Epstein-Barr (EB). Como se observou, a ideia de infecções recorrentes por vírus EB não era nova, tendo essa hipótese sido relatada ao longo dos anos anteriores.

\author{
(d) Dentro da discussão \\ mais ampla sobre \\ medicalização (muito \\ resumidamente, \\ a tradução para a \\ linguagem médica de \\ problemas anteriormente \\ vivenciados como não \\ médicos), há autores \\ que enfatizam a relação \\ entre o surgimento \\ de novos diagnósticos \\ e o lançamento de \\ remédios pela indústria \\ farmacêutica ${ }^{7,8}$. Não nos \\ aprofundaremos nessa \\ questão aqui. \\ (e) $\mathrm{O}$ debate sobre \\ a concepção saúde \\ e doença à luz \\ de concepções \\ socioantropológicas \\ é um campo amplo \\ que inclui vasta \\ bibliografia, a qual não \\ nos propomos debater \\ nesse artigo. Para os \\ fins do artigo, nos basta \\ definir que lidamos \\ com uma concepção \\ de saúde/doença \\ como processos não \\ meramente definidos \\ por medidas biomédicas, \\ mas como constructos \\ que dependem das \\ normas sociais, padrões \\ de normalidade e desvio \\ inseridos em diferentes \\ contextos culturais.
}

\footnotetext{
(f) O termo 'psicossocial', comumente empregado nas discussões sobre o burnout, aponta para a junção de duas áreas de compreensão das perturbações - o psíquico e o social. É uma categoria habitualmente empregada no campo dos saberes psi para marcar a importância de fatores ambientais ou sociais tanto na explicação de transtornos mentais quanto no seu tratamento. Não costuma ser usada entre cientistas sociais.
} 
(g) A expressão 'síndrome funcional' se aplica a diversas condições relacionadas entre si e caracterizadas mais por sintomas de sofrimento e incapacidade do que por anormalidades físicas demonstráveis anatomicamente ${ }^{10}$. A dificuldade na construção destes diagnósticos (devido a aspectos clínicos e técnicos) acaba mobilizando atores sociais diversos, como advogados, mídia, justiça, planos de saúde e pacientes, que, frequentemente, se organizam em busca da legitimidade de seus diagnósticos, fazendo de suas condições 'doenças que se tem que lutar para ter'11.

(h) A terceira definição da SFC conhecida como critérios de Oxford ${ }^{18}$, propunha que o diagnóstico fosse dado a sujeitos cujo principal sintoma fosse a fadiga com início definido, severa debilitante (afetando o funcionamento mental e físico), e presente por, no mínimo, seis meses. Excluem-se pacientes com outras condições médicas também produtoras de fadiga: esquizofrênicos e os então denominados maníaco-depressivos, drogadictos, e os com doenças cerebrais.
A SFC caracteriza-se por: exaustão incapacitante, cuja duração pode chegar a 24 horas após um esforço (nos casos em que há esforço precipitante), malestar, dores generalizadas, fraqueza muscular, aumento da temperatura corporal, linfonodos dolorosos, perturbações neuropsicológicas (memória, atenção e concentração) e cefaleias ${ }^{12}$. O diagnóstico vigora desde o fim da década de 1980, e tem recebido atenção e investigação, sobretudo na Inglaterra, Estados Unidos e Canadá.

Diferentes definições concorrem nos anos subsequentes à década de 1980, mas a mais aceita até hoje é a de Fukuda et al. ${ }^{13}$ (definição internacional). Revisão da primeira definição, de $1988^{14}$, ela aproveita muitos dos critérios anteriores. Requer a presença de fadiga persistente ou recorrente com início definido, e, no mínimo, quatro de oito queixas subjetivas específicas (prejuízo substancial na memória de curto prazo e na concentração, dor de garganta, sensibilidade nos linfonodos cervicais ou axilares, dor muscular, dor articular sem evidência de artrite, dores de cabeça de tipo diferente - em relação ao padrão e à gravidade - do costumeiro até então, sono não restaurador, mal-estar pós-exercício de duração maior que 24 horas). Os sintomas devem durar no mínimo seis meses.

Nenhum teste específico pode comprovar o diagnóstico de SFC, mas eles são usados para compor evidências e excluir outras condições. Dentre os testes requisitados, destacam-se: urina, hemograma completo, taxa de hemossedimentação, proteína total, proteína reativa, alanina aminotransferase, albumina, globulina, fosfatase alcalina, cálcio, fósforo, ureia sérica, eletrólitos, creatinina, hormônios da tireoide. Se nenhuma condição for detectada, o critério para SFC é satisfeito. Um diagnóstico bem realizado deve envolver o conhecimento de toda a história clínica do paciente, uma avaliação de sua saúde mental e do padrão de sono.

Segundo Abbey e Garfinkel ${ }^{15}$, a SFC se inicia, geralmente, entre vinte e quarenta anos, e afeta, ligeiramente, mais mulheres do que homens. Haveria dois padrões de desenvolvimento da doença: ela pode ser contínua, com melhora lenta, ou alternar recidivas constantes com períodos de melhora. Em ambos os casos, os sintomas podem levar à incapacidade laborativa e de manter as atividades sociais e pessoais. Já conforme Joyce et al. ${ }^{16}$, o prognóstico é variável. A maioria dos pacientes se recupera rapidamente, mas, em alguns casos, o quadro pode persistir por dois anos ou mais. Frequentemente, a doença segue um curso cíclico, alternando períodos de piora com outros de relativa saúde. Muitos pacientes avaliam que a gravidade dos sintomas varia de um dia para o outro e, portanto, ajustam seu nível de atividade em função dessa instabilidade. A melhora varia no período de 12 a 18 meses, e as taxas de piora nesse mesmo período alcançam 15-20\%. Há uma significante melhora espontânea.

Apesar dos números supracitados, reconhece-se a dificuldade em definir e diagnosticar a SFC, o que leva, inevitavelmente, à confusão na quantificação dos casos. Essa dificuldade, segundo Prins et al. ${ }^{17}$, afeta diretamente os estudos epidemiológicos, as estimativas variando de acordo com os critérios usados. Os autores ${ }^{17}$ apontam uma prevalência de 0,23\% a 0,42\% entre adultos nos Estados Unidos, sendo as taxas maiores em mulheres, membros de minorias sociais, pessoas com baixo nível de educação formal e baixo status ocupacional. Já no Reino Unido, utilizando-se os critérios de Oxford ${ }^{(h) 18}$, encontrou-se uma prevalência de 2,6\% na população de cuidados primários, mas esse número, possivelmente, incluía pacientes que se enquadram nos transtornos depressivos e ansiosos. Excluindo-se os pacientes com comorbidade psiquiátrica, a prevalência caía para 0,5\%. Em contrapartida, os critérios de 1988, excessivamente restritivos, excluindo, por exemplo, diversos transtornos psiquiátricos, produziam 
uma estimativa de $0,1 \%$. O relatório do grupo de trabalho dos Royal Colleges ${ }^{19}$ concluiu que a prevalência era de $1 \%$ a $2 \%$ na população, caindo para 0,1 a $0,7 \%$ se os transtornos psiquiátricos fossem excluídos.

A aparente imprecisão na definição da síndrome, levando a números discordantes, parece estar relacionada à dificuldade em delimitar as fronteiras entre o somático e o psíquico, no que tange a essa síndrome específica (e às síndromes funcionais de um modo geral), na medida em que a inclusão ou exclusão de transtornos psiquiátricos muda, substancialmente, os cálculos de prevalência. A fluidez de tais fronteiras é fortalecida pelo fato de, a despeito das insistentes pesquisas e avaliações serológicas, não ter surgido evidência convincente de um vírus responsável ou com papel determinante na patogênese da SFC20.

O fato de marcadores fisiológicos ou achados orgânicos específicos para a SFC não terem sido identificados abre caminho para hipóteses de que essa condição seja, primariamente, um transtorno psiquiátrico como a depressão ${ }^{21}$. É importante lembrar, porém, que a SFC apresenta sintomas não encontrados na depressão, tais como: dores de garganta recorrentes, linfonodos aumentados e febre, o que dificulta um equacionamento total entre esses transtornos. Wessely et al. ${ }^{22}$, por exemplo, defendem as diferenças entre depressão e SFC. Os pacientes de SFC não se queixam de perda de interesse nas atividades (como na depressão), mas de frustração em não serem capazes de realizá-las. O fato de a SFC não poder ser subsumida ao diagnóstico de depressão não implica, entretanto, que ela não possa ser compreendida pela via da psicopatologia. Ou seja, embora SFC e depressão possam ser vistos como diagnósticos distintos, isso não necessariamente elimina a possibilidade de uma hipótese psicogênica para a SFC.

Quanto ao tratamento, as estratégias são incertas e discutíveis, e envolvem o uso de agentes antivirais, analgésicos, ansiolíticos, antidepressivos, antagonistas do cálcio, suplementos de vitaminas e minerais. O relatório dos Royal Colleges ${ }^{19}$ enfatiza a importância de uma abordagem multidisciplinar, da aceitação dos sintomas do paciente e da formação de uma aliança terapêutica com ele. O uso de antidepressivos é aconselhado nos casos em que há um componente relacionado a esse transtorno do humor.

\section{Burnout}

As semelhanças entre burnout e SFC são também intrigantes, ainda que o primeiro não conste da lista de síndromes funcionais, por ser considerado de origem psicossocial.

O burnout surge como objeto científico em 1974, quando o psicanalista norte-americano Herbert Freudenberger descreve um quadro de esgotamento físico e mental ligado ao trabalho de voluntários em uma instituição de assistência a dependentes químicos. A expressão, de uso coloquial (significando algo como extinção, queima), passa então a definir um fenômeno de 'exaurimento de energia' decorrente de expectativas sociais ou individuais inatingíveis ${ }^{23}$.

Na mesma época, a psicóloga social Christina Maslach ${ }^{24}$ utiliza o mesmo termo para designar uma reação semelhante observada em profissionais de cuidados/serviços (os chamados human services). Sua definição de burnout como uma 'síndrome psicológica em resposta a estressores interpessoais crônicos no trabalho', composta por três dimensões - exaustão emocional (sensação de depleção de recursos físicos e emocionais), despersonalização (reação negativa ou excessivamente distanciada em relação aos clientes) e redução da realização pessoal (sentimentos de incompetência e de perda de produtividade) -, acaba por tornar-se referência ${ }^{25}$.

A criação do MBI (Maslach Burnout Inventory) populariza o conceito na área acadêmica, estendendo a pesquisa a outros campos (notadamente, a saúde ocupacional, além de psicologia organizacional, enfermagem e medicina). Também permite a produção de dados estatísticos em escala internacional, bem como a expansão de sua aplicação às mais diversas categorias profissionais, por meio das versões para trabalhadores da saúde (MBI-HSS - health services survey), professores (MBI-ES - education survey) e geral (MBI-GS - general survey) ${ }^{25}$. 
(i) Para exaustão (enfatizando as manifestações físicas e cognitivas de fadiga, e, menos, o aspecto emocional), cinismo (conduta insensível e desengajada com relação ao trabalho de forma global) e redução da eficácia (sentimentos de ineficiência).

(j) Stress é o termo usado pelo fisiologista Hans Selye, em 1936, para designar uma 'síndrome geral de adaptação' sofrida pelo corpo para responder às demandas a ele impostas, e tomado por Walter Cannon em suas pesquisas sobre os mecanismos de luta ou fuga (em 1956) ${ }^{27}$. Posteriormente, foi adotado por teorias psicológicas e do campo da chamada Psicologia do Trabalho, havendo, assim, um deslocamento de seu sentido inicial para outros campos interpretativos.
Com isso, o próprio conceito de burnout sofreu reformulações (refletidas na renomeação da tríade dimensional) ${ }^{(i)}$, no sentido de destacar a relação com o trabalho em si - não especificamente com as pessoas com quem se trabalha ${ }^{25}$. Além disso, conceitos alternativos têm sido propostos, na tentativa de aprimorar ou, mesmo, substituir a noção dominante de Maslach e colaboradores (considerada frágil do ponto de vista teórico-metodológico por alguns pesquisadores) ${ }^{26}$.

O conceito de burnout está estreitamente ligado ao de estresse ${ }^{(j)}$, como demonstra o uso recorrente da expressão 'reação ao estresse crônico ocupacional'28 para defini-lo. A exaustão é considerada o núcleo do fenômeno. A despersonalização/cinismo corresponderia, para alguns teóricos, à noção de desengajamento (perda de identificação e desenvolvimento de uma espécie de 'aversão'/rejeição ao trabalho) ${ }^{29}$, enquanto a realização pessoal tende a ser excluída do conceito ${ }^{28}$.

Compreendido como uma condição crônica ${ }^{28}$, sua prevalência varia em função da metodologia e da população estudada, com taxas entre $7 \%$ e $17,9 \%$ em amostras de população geral ativa ${ }^{30}$. Tem sido associado a consequências para a saúde física e mental, como: aumento do risco cardiovascular ${ }^{31}$, diabetes tipo $2^{32}$, distúrbios musculoesqueléticos ${ }^{33}$ e, especialmente, depressão ${ }^{34}$. Provocaria, ainda, grande impacto socioeconômico, produzindo absenteísmo ${ }^{35}$ e aposentadoria precoce ${ }^{36}$, e elevando gastos previdenciários e de saúde.

Burnout e depressão compartilham a queixa de exaustão/fadiga ou baixa energia. Estudos demonstram, no entanto, tratar-se de conceitos distintos, embora frequentemente associados ${ }^{34,37}$. Comparado à depressão, o burnout seria mais restrito ao contexto laboral - pelo menos, no início do quadro (enquanto a depressão atingiria todas as esferas da vida); cursaria com menos perda de peso, inibição psicomotora, sentimentos de culpa e anedonia (o indivíduo com burnout é mais capaz de sentir prazer nas atividades, porém não tem energia suficiente para engajar-se nelas); teria a indecisão e a inatividade mais facilmente atribuídas à fadiga do que à própria doença (como fazem, geralmente, os pacientes deprimidos); se associaria à insônia inicial ou intermediária (e não, à insônia terminal, como na depressão típica) ${ }^{37}$.

Em estágios avançados, o burnout pode generalizar-se para além de seu(s) contexto(s) específico(s), tornando-se difícil distingui-lo da depressão clínica. Para explicar a associação entre as duas condições, algumas hipóteses levantadas são a de uma etiologia comum (ligada a antecedentes comuns, como o estresse crônico, ou à vulnerabilidade individual, como neuroticismo ${ }^{28}$, podendo o burnout ser uma fase precursora da depressão ${ }^{34}$. Ou haveria um subtipo de burnout, qualitativamente semelhante à depressão e com pior prognóstico ${ }^{38}$. As duas condições poderiam ainda coexistir, levando a uma sintomatologia diferente da de cada síndrome em separado ${ }^{38}$.

Apesar da tradicional associação ${ }^{23}$ a características pessoais de dedicação extrema e autoexigência de desempenho (relacionadas, por sua vez, às atividades de cuidado ou de excessiva responsabilidade), considera-se que os principais determinantes do burnout são as más condições do ambiente de trabalho: sobrecarga, pressão de tempo, demandas conflitantes, falta de autonomia e de apoio social, problemas referentes a hierarquia, regras de operação, recursos e distribuição espacial ${ }^{25}$. Tais condições decorreriam das recentes transformações do mundo do trabalho envolvendo: restruturação produtiva, demissões em massa, precarização e a exigência crescente de trabalhadores 'polivalentes'. 
O status nosológico do burnout é controverso. Em geral, lida-se com ele de maneira análoga a uma doença: é 'diagnosticado' por meio de um inventário de 'sintomas' (o MBI), e tratado por meio de psicoterapia e/ou medicamentos. O grau de medicalização, entretanto, varia de país para país ${ }^{39}$. Na Suécia, ele alcançou a condição de transtorno psiquiátrico ('transtorno de exaustão'), codificável como CID-10 F43.8. Na Holanda, utiliza-se a categoria neurastenia, com a especificação 'relacionada ao trabalho' (CID-10 F48.0). Por outro lado, nos EUA, a rejeição ao rótulo/estigma de doença mental é mais forte, optando-se por não transformar o burnout em diagnóstico psiquiátrico.

No Brasil, desde 1999, o burnout integra a lista de doenças relacionadas ao trabalho do Ministério da Saúde, aí constando como transtorno mental, sob o código CID-10 Z73.0 ('sensação de estar acabado'/'esgotamento') ${ }^{40}$. Apesar disso, permanece pouco reconhecido nos âmbitos previdenciário e médico em geral.

A indefinição do status nosológico do burnout se reflete na questão de seu tratamento e prevenção. A rigor, não há o que se possa chamar de um tratamento específico para burnout. Habitualmente, as intervenções visam o controle do estresse ocupacional de forma geral, podendo ser orientadas para: o indivíduo (psicoterapia cognitivo-comportamental, exercícios de relaxamento, counseling, apoio social); a organização do trabalho (restruturação de processo de trabalho, avaliações de desempenho, readequação de turnos); ou combinadas (para promover um ajustamento entre indivíduo e organização) ${ }^{41}$. Há, também, a reabilitação profissional, cujo objetivo é manter a capacidade laborativa, geralmente por meio do aumento da resistência individual aos estressores ocupacionais ${ }^{42}$. Porém, ainda há poucos estudos sobre este tópico. Nossa impressão, baseada em análise superficial da literatura internacional e em conhecimento da experiência clínica brasileira, é de que a preferência tem recaído sobre a psicoterapia individual ou de grupo.

\section{Discussão}

SFC e burnout são diagnósticos que, dirigidos para uma queixa semelhante (cansaço extremo cuja etiologia é contestada, no caso do primeiro, ou vista como psicossocial, no caso do segundo), convertem-se facilmente em objeto de controvérsias. Aproximam-se do universo psiquiátrico, confundindo-se, às vezes, com o diagnóstico de depressão. Mas essa aproximação se dá a partir de campos opostos: o burnout nasce como um diagnóstico psicossocial, e a SFC como um diagnóstico médico, permanecendo como condições pertencentes à CID (Classificação Internacional de Doenças), mas não ao DSM (Diagnostic and Statistical Manual of Mental Disorders). De qualquer modo, ambos habitam esse espaço um tanto confuso em que se busca delimitar a distinção entre as perturbações classificadas como somáticas e aquelas classificadas como psíquicas.

A confusão em torno dos diagnósticos de fadiga se reflete em suas diferentes inserções em vários sistemas classificatórios (não apenas CID e DSM, mas, também, sistemas locais de registro de doenças - para fins previdenciários, por exemplo ${ }^{43}$. Assim, a CID-10 permite classificar a SFC como transtorno neurológico, na categoria correspondente à encefalite miálgica ou 'síndrome de fadiga pós-viral' (G93.3), ao mesmo tempo em que a considera, sob a expressão 'síndrome de fadiga', como sinônimo de neurastenia (F48.0), o que possibilita seu enquadramento como transtorno mental. Há, ainda, a rubrica R53 ('mal-estar e fadiga') que, usada para descrever afecções mal definidas de etiologia desconhecida, também é, por vezes, indicada como possível código para SFC ${ }^{44}$.

Já o burnout, apesar de representar, na CID-10, um 'problema que leva ao contato com serviços de saúde' (código Z) - e não, uma doença propriamente dita -, foi equiparado a transtorno mental em alguns países europeus. O que se vê, nesses casos, é um uso local da CID-10, adaptado em função de necessidades sociais e de determinadas visões culturais sobre o adoecimento, podendo refletir, ainda, uma maior legitimidade social dos transtornos mentais.

Por sua vez, o DSM não menciona nem SFC, nem burnout. Observe-se, entretanto, que a impossibilidade do reconhecimento como transtorno psiquiátrico é oficial, mas, também, social, na medida em que parece estar relacionada à questão do estigma da doença mental. 
A partir das reflexões de Greco ${ }^{45}$, assinalamos dois pontos relevantes no que tange ao peso moral da distinção somático $\mathrm{x}$ psíquico. A autora chama atenção para o status hierárquico inferior das condições sem origem orgânica clara, indicando que, nesses casos, elas perpetuam o estigma da doença mental. A 'doença do corpo' se diferenciou da 'da mente' pela irrelevância da dimensão volicional na compreensão da primeira, e pela centralidade dela na segunda. Disso decorre que a doença com etiologia incerta ou cuja etiologia é psicossocial seja compreendida como um problema moral do sofredor e inteiramente de sua responsabilidade.

Outro ponto destacado pela autora é a emergência, na segunda metade do século XIX, de práticas de seguro e indenização relacionadas aos perigos do trabalho e da indústria, o que provocou uma mudança na percepção da saúde daquele que trabalha como uma condição crucial tanto para a participação social (por parte dos trabalhadores) quanto para a obtenção de lucro/produtividade (por parte dos empregadores). Por outro lado, fez surgir a ideia de que a doença pode constituir uma oportunidade de deserção moralmente disfarçada e impune da função legitimada para cada um na sociedade, que é, sobretudo, o trabalho.

O conceito de doença centrado no mecanismo biológico torna-se, assim, o princípio de realidade que servirá para discriminar entre uma necessidade genuína de cuidado e uma demanda injustificada (caso da simulação). A presença objetiva de um achado no corpo é considerada prova de que as desvantagens de uma dada condição clínica são maiores do que as vantagens que podem derivar dela (relativas à ausência/licença do trabalho). Constitui, assim, ferramenta para desconsiderar o ponto de vista motivacional, tornando patológica - mais do que desviante - a condição existente.

Ainda que este artigo não se proponha a analisar exaustivamente o campo da sociologia do trabalho, sustentamos a hipótese de uma relação de ambas as categorias aqui tratadas com as formas de relação de produção e as exigências do mundo do trabalho. A percepção de (in)capacidade laborativa é uma dimensão do reconhecimento social, tanto da SFC quanto do burnout - mesmo que a referência ao trabalho pareça, inicialmente, distingui-los. Aqui cabe ressaltar o aspecto da distribuição geográfica diferencial das duas categorias. Burnout tem mais sucesso em países europeus adeptos dos modelos de bem-estar social, onde a população percebe o Estado como provedor de bem-estar e há uma forte noção de proteção ao trabalho e a possíveis dificuldades do trabalhador. Neste contexto, as causas '(psico)sociais' para a incapacidade são mais aceitáveis. SFC parece ter mais sucesso nos EUA, onde a ideia de leis de proteção ao trabalho e ao trabalhador é fraca, e se enfatiza o 'empreendedorismo' dos indivíduos e sua capacidade de sobreviver sem a ajuda do Estado. Uma doença orgânica, que desculpabiliza o sujeito, pode assim ser vista como uma explicação mais legítima para o 'fracasso pessoal'.

O contexto sociocultural de emergência de cada uma das categorias - enquanto explicação para um sintoma semelhante - pode ser entendido segundo duas perspectivas: uma mais imediata (alguns anos ou décadas) e outra mais ampla, de longo prazo (várias décadas ou séculos).

No primeiro caso, uma pequena, porém significativa, defasagem temporal irá, acreditamos, produzir uma importante diferença no modo como cada categoria se difunde.

A SFC surge no âmbito da medicina e do raciocínio biológico nos anos 1980, associada a quadros supostamente pós-infecciosos. Nessa década, importantes transformações socioculturais ocorrem nos países desenvolvidos (em especial, o mundo anglo-saxão). De um lado, a razão biológica parece ganhar, cada vez mais, força em detrimento de explicações psicológicas para os transtornos humanos. De outro, o mundo do trabalho passa por transformações que vão, pouco a pouco, mudar sua face.

Aronowitz ${ }^{46}$ analisa a emergência da SFC como relacionada a uma 'disponibilidade cultural' após os antecedentes da pólio atípica e da encefalite miálgica, resultando numa percepção/consciência aumentada para a doença. Entre os 'determinantes não biológicos' dessa construção de doença, destacam-se: as 'crenças e atitudes leigas e médicas' (a ideia da desregulação do sistema imune, que, por sua vez, é provocada pelo estresse, assim "provendo um elo pseudobiológico entre um vírus incitante, eventos vitais e doença") ${ }^{46}$ (p. 165); e as 'relações ecológicas', i.e., a interdependência entre doenças proeminentes em determinada época e lugar (no caso, a epidemia de aids, também viral, também afetando o sistema imune, e também atacando grupos sociais específicos e sujeitos a 
estigma). Em outros termos, o diagnóstico de SFC organiza e procura atribuir sentido a um conjunto de sintomas díspares e fracamente interligados, em um momento em que as noções de fraqueza imunológica e infecções virais atípicas ganham espaço tanto no imaginário médico quanto no imaginário do público leigo de modo geral. Ao mesmo tempo, aponta para a leitura orgânica de perturbações que, por suas características, poderiam ser consideradas psicológicas.

Já o burnout emerge no campo da psicologia - e em referência direta aos profissionais dos human services - em um contexto sociocultural inteiramente diverso. Schaufeli et al. ${ }^{39}$ identificam, nos Estados Unidos da década de 1960, as raízes do fenômeno que, na década seguinte, veio a ser conhecido como burnout. Os anos 1960 são marcados pelo surgimento da contracultura, pela intensificação do ativismo social, e, também, por um maior foco governamental no serviço público e no combate à pobreza. Tudo isso levou as profissões de cuidado a uma maior preocupação com questões de cidadania e liberdade individual, e a um maior idealismo profissional. Na década de 1970, segue-se uma forte frustração nesses meios profissionais, devido à não-concretização dos ideais libertários então valorizados. Ao mesmo tempo, este também é um momento de contestação das instituições em geral (e da instituição médica em particular). Esse fato, associado a importantes mudanças nas profissões de cuidado (da ênfase na vocação para a burocratização/gestão 'técnica' da atividade profissional), acabará levando à perda de prestígio social e ao desencantamento com a profissão. O burnout teria aparecido em meio a esse contexto de intensa ebulição, entre profissionais das chamadas free clinics $^{(k)}$, como uma espécie de reação a essa frustração.

Os ideais que moveram tais expectativas teriam propiciado, aos profissionais do cuidado, maior abertura para explicações psicológicas e sociais de seus (próprios) problemas de saúde ${ }^{39}$. Ao lado disso, uma transformação na perspectiva científica relativa aos transtornos mentais teria ajudado - de forma aparentemente paradoxal - a fortalecer o enfoque psicossocial. Especificamente no campo das doenças ocupacionais, Leone et al. ${ }^{43}$ apontam a mudança de uma visão 'culpabilizante' - representada pela noção de neurose - da doença profissional (considerada como causada exclusivamente pelo temperamento e personalidade individuais) para uma visão que admite fatores externos ao indivíduo (como o ambiente de trabalho) como causa de adoecimento psíquico. Tal mudança teria se dado a partir da introdução da categoria 'transtorno de estresse pós-traumático' (TEPT) no DSM-III, em 1980. Assim, é o TEPT - e o abandono da noção de neurose - que torna possível atribuir o adoecimento mental a algo originalmente exterior ao sujeito(l).

O abandono da noção de neurose em favor da noção de estresse (traumático) acabaria, também, por favorecer o uso civil de uma "nova concepção de vítima: vítimas de atentados, [...] estupros, [...] agressão, mas também assalariados traumatizados no contexto de seu trabalho" 50 (p. 127). Teria havido, então, uma abertura para as explicações ambientais (manifestadas na organização do trabalho) na mesma época em que o burnout se popularizava no meio acadêmico.

Na perspectiva de longo prazo, os dois fenômenos podem ser vistos como resultantes de uma intensificação do processo de individualização, com duas vertentes: biologizante (SFC) e psicologizante (burnout).

A exacerbação de uma compreensão individualista do mundo é o pano de fundo cultural que leva, progressivamente, à crença de que o fracasso ou o

(k) Organizações privadas, sem fins lucrativos, que oferecem serviços básicos de saúde a pacientes não segurados nos EUA, prestados por médicos voluntários (em geral), gratuitamente ou a baixo custo. Sua origem remete a 1967, quando da fundação da Haight Ashbury Free Medical Clinic, em São Francisco (Califórnia), por iniciativa do médico David Smith, cujo intuito era prestar assistência aos muitos jovens que se concentraram nesta cidade no contexto do movimento hippie ${ }^{47}$

\footnotetext{
(1) Há quem objete

a relação desses

transtornos relacionados

à fadiga com o TEPT.

Essa é uma associação,

a nosso ver, equivocada,

já que os sintomas desse último passam ao largo

da fadiga e indicam o

que se tem chamado de tríade psicopatológica em resposta ao evento traumático previamente vivenciado, qual seja, a reexperimentação do evento traumático, a evitação de possíveis estímulos associados a ele e a presença de hiperestimulação autonômica ${ }^{48}$. O ponto em comum - que não nos permite, contudo, colocar as classificações tratadas no artigo em série com o TEPT - é a condição controversa das três classificaçõos. Sobre esse ponto, há que se ressaltar o trabalho de Young ${ }^{49} \mathrm{em}$ reconstruir com detalhes o trabalho da construção desses 'achados fidedignos' em grupos de pesquisa internacionais que buscam biomarcadores do TEPT. Nesse sentido, a busca por uma 'coisa epistemológica' - no caso do TEPT, o hipocortisolismo - tem a utilidade de justificar e legitimar os sintomas sem lesão, sendo essa busca o principal ponto de contato com as categorias aqui analisadas.
} 
sucesso pessoal se devem, exclusivamente, à responsabilidade e ao esforço do indivíduo. Ao mesmo tempo, uma série de mudanças sociais no mundo do trabalho ocorridas nas duas últimas décadas do século $X X$ - o rápido declínio de algumas atividades tradicionais, com a ascensão de outras que apontam para novas possibilidades de enriquecimento individual e para uma concorrência exacerbada pelos novos postos e pela boa remuneração - refletem-se, nas grandes empresas, em novas exigências de flexibilidade e criatividade no enfrentamento de problemas. A ênfase no 'talento' do indivíduo para adaptar-se às novas demandas, valorizando sua autonomia e individualidade, oculta o caráter social e coercitivo das mesmas.

$\mathrm{Se}$, por um lado, cria-se um meio extremamente propício para que o mal-estar seja compreendido por meio de uma explicação viral ou somática - como no caso da SFC, florescente em meios sociais que valorizam muito a autonomia pessoal -, por outro lado, mesmo entre o 'público' dos profissionais de cuidado/serviços - que admitem mais facilmente a existência de coerções sociais e interdependências ${ }^{51}$ - a abordagem dita psicossocial parece oscilar entre um polo mais próximo à ideia de causalidade social das perturbações e outro polo em que o 'psicológico' se sobrepõe como determinante, devendo o indivíduo aprender a dominar suas emoções para não adoecer (mas, também, para se manter como um 'bom' trabalhador, i.e., aquele que responde adequadamente às exigências desse novo mundo do trabalho). É nesse sentido que alguns pesquisadores franceses da sociologia do trabalho (como Marc Loriol, Valérie Boussard, Marie Buscatto) veem no burnout um caso de 'psicologização' das questões laborais, constituindo-se em uma outra forma de individualização, calcada na ênfase na 'singularidade' (o 'eu' íntimo, autêntico, revelado por meio do trabalho) e no desenvolvimento de uma moral do florescimento (épanouissement) pessoal ${ }^{52}$.

A noção de estresse tem promovido, cada vez mais, uma linguagem comum entre a 'biologização' representada pela SFC e a 'psicologização' do burnout.

Estresse é uma categoria suficientemente difusa para se prestar aos dois tipos de leitura: é mais psicológica que um vírus, ao mesmo tempo em que parece menos mental (e, portanto, mais física) que desejos inconscientes ou frustração, comportando tanto novos modelos fisiológicos (carga alostática, teoria da ativação cognitiva $)^{53}$, quanto velhos modelos psicossociais. Seu sentido de origem vincula-a ao stress propriamente físico ou material (alusivo à força capaz de deformar um corpo), sendo o sentido mais psicológico e médico secundário a esse primeiro. Tanto circula no senso comum, para explicar perturbações humanas do cotidiano, quanto em discussões acadêmicas. Logo, é facilmente compreensível por quem a utiliza, mas, talvez por isso mesmo, pouco precisa. Essa imprecisão torna-a uma categoria interessante para ser utilizada nesse espaço intermediário (e, também, pouco preciso) entre o somático e o psíquico.

É necessário, contudo, acrescentar uma terceira dimensão a esse espaço intermediário: o social. O caso do burnout, cuja relação com o ambiente laboral é crucial, evidencia a existência de fronteiras fluidas e pouco definidas não apenas entre o somático e o psíquico, mas, também, entre essas duas esferas e a dimensão social. O estresse, então, pode ser pensado como um produto do ambiente (pressões e coerções sociais) que gera efeitos psicológicos e físicos importantes. É uma categoria, neste sentido, que pode dar conta da circulação entre essas três dimensões, sendo assim, por excelência, 'biopsicossocial'. Ao mesmo tempo, os novos modelos fisiológicos do estresse permitem sua aproximação a síndromes funcionais, como a SFC, por meio do denominador comum das "queixas subjetivas de saúde" 53 (p. 445).

Finalizamos assinalando que, na comparação entre as duas categorias diagnósticas, algumas questões importantes se cruzam: a oposição e/ou complementaridade entre uma visão biológica e outra psicossocial, das perturbações; o contexto sociocultural de emergência de diferentes categorias diagnósticas; e, por fim, a estruturação sociopolítica do mundo do trabalho. Reconhecemos que um tema importante - a relevância do trabalho como fonte de estruturação da subjetividade moderna e contemporânea - não foi abordado aqui. Nossa pretensão, entretanto, não foi a de esgotar a discussão acerca das duas categorias, buscando tão somente fornecer subsídios para estudos posteriores, em especial, estudos sobre seu uso (ou a ausência dele) em nosso país. 


\section{Colaboradores}

Os autores participaram, igualmente, de todas as etapas de elaboração do artigo.

\section{Referências}

1. Brown P. Naming and framing: the social construction of diagnosis and illness. J Health Soc Behav. 1995; 35 Spec N:34-52.

2. Jutel A. Classification, diagnosis and disease. Perspect Biol Med. 2011; 54(2):189-205.

3. Bury M. Chronic illness as biographical disruption. Sociol Health Illn. 1982; 4(2):167-82.

4. Charmaz K. Loss of self: a fundamental form of suffering in the chronically ill. Sociol Health Illn. 1983; 5(2):168-95.

5. Williams G. The genesis of chronic illness: narrative reconstruction. Sociol Health Illn. 1984; 6(2):175-200.

6. Tekin S. The missing self in Hacking's looping effects. In: Kincaid H, Sullivan JA, editors. Classifying psychopathology: mental kinds and natural kinds. Massachussets: MIT Press; 2014. p. 227-56.

7. Conrad P. The medicalization of society: on the transformation of human conditions into treatable disorders. Baltimore: The Johns Hopkins University Press; 2007.

8. Dumit J. Drugs for life: how pharmaceutical companies define our health. Durham: Duke University Press; 2012.

9. Zorzanelli RT. A fadiga e seus transtornos: condições de possibilidade, ascensão e queda da neurastenia novecentista. Hist Cienc Saude - Manguinhos. 2009; 16(3):605-20.

10. Barsky A, Borus J. Functional somatic syndromes. Ann Intern Med. 1999; 130(11):910-21.

11. Dumit J. Illnesses you have to fight to get: facts as forces in uncertain, emergent illnesses. Soc Sci Med. 2006; 62(3):577-90.

12. Wessely S. Neurasthenia and fatigue syndromes: clinical section. In: Berrios GE, Porter $\mathrm{R}$, editors. A history of clinical psychiatry: the origins and history of psychiatry disorders. London: Athlone; 1995. p. 509-32.

13. Fukuda K, Straus S, Hickie I, Sharpe MC, Dobbins JG, Komaroff A. The chronic fatigue syndrome: a comprehensive approach to its definition and study. International Chronic Fatigue Syndrome Study Group. Ann Intern Med. 1994; 121(12):953-9.

14. Holmes GP, Kaplan J, Nelson MG, Komaroff AL, Schonberger LB, Straus SE. Chronic fatigue syndrome: a working case definition. Ann Intern Med. 1988; 108(3):387-89.

15. Abbey S, Garfinkel, P. Neurasthenia and Chronic Fatigue Syndrome: the role of culture in the making of diagnosis. Am J Psychiatry. 1991; 148(12):1638-46.

16. Joyce J, Hotopf $M$, Wessely $S$. The prognosis of chronic fatigue and chronic fatigue syndrome: a systematic review. Q J Med. 1997; 90(3):223-33.

17. Prins J, van der Meer J, Bleijenberg G. Chronic fatigue syndrome. Lancet. 2006; 367(9507):346-55.

18. Sharpe MC, Archard LC, Banatvala JE, Borysiewicz LK, Clare AW, David A, et al. A report - chronic fatigue syndrome: guidelines for research. J R Soc Med. 1991; 84(2):118-21.

19. Royal College of Physicians, Royal College of Psychiatrists, Royal College of General Practitioners. Chronic Fatigue Syndrome: report of a joint working group of the Royal Colleges of Physicians, Psychiatrists and General Practitioners. London: Royal College of Physicians Publication Unit; 1996. (Council Report CR54). 
20. Komaroff A, Goldenberg D. The chronic fatigue syndrome definition, current studies and lessons for fibromyalgia research. J Rheumatol Suppl. 1989; 19:23-7.

21. Afari N, Buchwald D. Chronic fatigue syndrome: a review. Am J Psychiatr. 2003; 60(2):221-36.

22. Wessely $S$, Hotopf $M$, Sharpe $M$. Chronic fatigue syndrome and its syndromes. New York: Oxford University Press; 1998.

23. Freudenberger HJ. Staff burnout. J Soc Issues. 1974; 30(1):159-65.

24. Maslach C. Burned-out. Hum Behav. 1976; 5(9):16-22.

25. Maslach C, Schaufeli WB, Leiter MP. Job burnout. Ann Rev Psychol. 2001; 52:397-422.

26. Vieira I. Conceito(s) de burnout: questões atuais da pesquisa e a contribuiçãa da clínica. Rev Bras Saude Ocup. 2010; 35(122):269-76.

27. Selye H. Stress, a tensão da vida. São Paulo: Ibrasa - Instituição Brasileira de Difusão Cultural; 1959.

28. Shirom A, Melamed S, Toker S, Berliner S, Shapira I. Burnout, mental and physical health: a review of the evidence and a proposed explanatory model. Int Rev Ind Organ Psychol. 2005; 20:269-309.

29. Demerouti $E$, Bakker AB, Vardakou I, Kantas A. The convergent validity of two burnout instruments: a multitrait-multimethod analysis. Eur J Psychol Assess. 2003; 19(1):12-23.

30. Lindblom K, Linton S, Fedeli C, Bryngelsson I. Burnout in the working population: relations to psychosocial work factors. Int J Behav Med. 2006; 13(1):51-9.

31. Toker S, Melamed S, Berliner S, Zeltser D, Shapira I. Burnout and risk of coronary heart disease: a prospective study of 8838 employees. Psychosom Med. 2012; 74(8):840-7.

32. Melamed S, Shirom A, Toker S, Shapira I. Burnout and risk of type 2 diabetes: a prospective study of apparently healthy employed persons. Psychosom Med. 2006; 68(6):863-9.

33. Armon G, Melamed S, Shirom A, Shapira I. Elevated burnout predicts the onset of musculoskeletal pain among apparently healthy employees. J Occup Health Psychol. 2010; 15(4):399-408.

34. Ahola K, Honkonen T, Isometsä E, Kalimo R, Nykyri E, Aromaa A, et al. The relationship between job related burnout and depressive disorders: results from the Finnish Health 2000 Study. J Affect Disord. 2005; 88(1):55-62.

35. Ahola K, Kivimäki M, Honkonen T, Virtanen T, Koskinen S, Vahtera J, et al. Occupational burnout and medically certified sickness absence: a population-based study of Finnish employees. J Psychosom Res. 2008; 64(2):185-93.

36. Weber A, Weltle $D$, Lederer P. III health and early retirement among school principals in Bavaria. Int Arch Occup Environ Health. 2005; 78(4):325-31.

37. Brenninkmeyer V, van Yperen NW, Buunk BP. Burnout and depression are not identical twins: is decline of superiority a distinguishing feature? Pers Individ Dif. 2001; 30(5):873-80.

38. Iacovides A, Fountoulakis KN, Kaprinis S, Kaprinis G. The relationship between job stress, burnout and clinical depression. J Affect Disord. 2003; 75(3):209-21.

39. Schaufeli WB, Leiter MP, Maslach C. Burnout: 35 years of research and practice. Career Dev Int. 2009; 14(3):204-20.

40. Portaria $\mathrm{n}^{\circ} 1.339 / \mathrm{GM} / \mathrm{MS}$, de 18 de novembro de 1999. Institui a Lista de doenças relacionadas ao trabalho. Diário Oficial da União. 19 Nov 1999. 
41. Awa W, Plaumann $M$, Walter U. Burnout prevention: a review of intervention programs. Patient Educ Couns. 2010; 78(2):184-90.

42. Hätinen $M$, Kinnunen $U$, Mäkikangas $A$, Kalimo R, Tolvanen A, Pekkonen M. Burnout during a long-term rehabilitation: comparing low burnout, high burnout - benefited, and high burnout - not benefited trajectories. Anxiety Stress Coping. 2009; 22(3):341-60.

43. Leone SS, Wessely S, Huibers MJ, Knottnerus JA, Kant I. Two sides of the same coin? On the history and phenomenology of chronic fatigue and burnout. Psychol Health. 2011; 26(4):449-64.

44. Sadock BJ, Sadock VA, organizadores. Chronic fatigue syndrome and neurasthenia. In: Kaplan \& Sadock's synopsis of psychiatry: behavioral sciences, clinical psychiatry. 9a ed. Philadelphia: Lippincott Williams \& Wilkins; 2003. p. 661-7.

45. Greco M. Psychosomatic subjects and the "duty to be well": personal agency within medical rationality. Econ Soc. 1993; 22(3):357-72.

46. Aronowitz RA. From myalgic encephalitis to yuppie flu: a history of chronic fatigue syndromes. In: Rosenberg C, Golden J, editors. Framing disease: studies in cultural history. New Jersey: Rutger University Press; 1992. p. 155-81.

47. Weiss GL. Grassroots medicine: the story of America's free health clinics. Lanham: Rowman \& Littlefield Publishers; 2006.

48. Figueira I, Mendlowicz M. Diagnóstico do transtorno de estresse pós-traumático. Rev Bras Psiquiatr. 2003; 25 Supl 1:S12-6.

49. Young A. Our traumatic neurosis. Sci Context. 2001; 14(4):661-83.

50. Loriol M. La construction du social: souffrance, travail et catégorisation des usagers dans I'action publique. Rennes: Presses Universitaires de Rennes; 2012.

51. Loriol M. Le temps de la fatigue: la gestion sociale du mal-être au travail. Paris: Anthropos; 2000.

52. Loriol M. Les ressorts de la psychologisation des difficultés au travail. Une comparaison entre infirmières, policiers et conducteurs de bus. Cah Rech Sociol. 2005; (41-42):191208.

53. Eriksen HR, Ursin H. Subjective health complaints, sensitization, and sustained cognitive activation (stress). J Psychosom Res. 2004; 56(4):445-8.

Zorzanelli R, Vieira I, Russo JA. Diversos nombres para el cansancio: categorías emergentes y su relación con el mundo del trabajo. Interface (Botucatu). 2016; 20(56):77-88.

El objetivo de este artículo es explorar, desde el punto de vista sociocultural, la emergencia de dos entidades clínicas entre 1970 y 1980 que, en el campo de la clínica general y de los saberes psi, dan nombre a cuadros centrados en el síntoma de la fatiga: el síndrome de la fatiga crónica (CID-10 G93.3) y el burnout (CID-10 Z73.0). Pretendemos, después de una breve presentación de ambas, analizar el surgimiento de esas categorías, para indicar el cansancio y el agotamiento como síntomas que hay que tratar médicamente y explorar los puntos de aproximación y de separación entre ellas.

Palabras clave: Fatiga. Síndrome de la fatiga crónica. Agotamiento profesional. Trabajo. Sociología médica. 